\title{
Optimisation and modelling of supercritical CO2 extraction process of carotenoids from carrot peels
}

Article

Accepted Version

Creative Commons: Attribution-Noncommercial-No Derivative Works 4.0

de Andrade Lima, M., Charalampopoulos, D. and Chatzifragkou, A. (2018) Optimisation and modelling of supercritical $\mathrm{CO} 2$ extraction process of carotenoids from carrot peels. The Journal of Supercritical Fluids, 133. pp. 94-102. ISSN 0896-8446 doi:

https://doi.org/10.1016/j.supflu.2017.09.028 Available at https://centaur.reading.ac.uk/73058/

It is advisable to refer to the publisher's version if you intend to cite from the work. See Guidance on citing.

Published version at: http://www.sciencedirect.com/science/article/pii/S0896844617304679

To link to this article DOI: http://dx.doi.org/10.1016/j.supflu.2017.09.028

Publisher: Elsevier

All outputs in CentAUR are protected by Intellectual Property Rights law, including copyright law. Copyright and IPR is retained by the creators or other copyright holders. Terms and conditions for use of this material are defined in the End User Agreement. 


\section{CentAUR}

Central Archive at the University of Reading

Reading's research outputs online 


\title{
Optimisation and modelling of supercritical $\mathrm{CO}_{2}$ extraction process of carotenoids from carrot peels
}

\author{
Micael de Andrade Lima, Dimitris Charalampopoulos, Afroditi Chatzifragkou* \\ Department of Food and Nutritional Sciences, University of Reading, Whiteknights, PO Box 226, \\ Reading, RG6 6AP, UK \\ *Corresponding author: a.chatzifragkou@ reading.ac.uk
}

\begin{abstract}
This work aimed to assess and optimise the extraction of carotenoids from carrot peels by supercritical $\mathrm{CO}_{2}\left(\mathrm{~S}-\mathrm{CO}_{2}\right)$, utilising ethanol as co-solvent. The evaluated variables were temperature, pressure and co-solvent concentration. According to the validated model, the optimal conditions for maximum mass yield $\left(5.31 \%\right.$, d.b.) were found at $58.5{ }^{\circ} \mathrm{C}, 306$ bar and $14.3 \%$ of ethanol, and at 59.0 ${ }^{\circ} \mathrm{C}, 349$ bar and $15.5 \%$ ethanol for carotenoid recovery $(86.1 \%)$. Kinetic experiments showed that $97 \%$ of the total extractable carotenoid content was recovered after only $30 \mathrm{~min}$, whereas model fitting confirmed the fast extraction trend and desorbing nature of carotenoids from the sample matrix. The process is potentially scalable, as demonstrated by runs performed with a 10 -fold initial sample size, which led to even higher recoveries $(96.7 \%)$, indicating that $\mathrm{S}-\mathrm{CO}_{2}$ can be as efficient as a conventional solvent extraction for recovering high value compounds from vegetable by-products.
\end{abstract}

Keywords: carotenoids; supercritical $\mathrm{CO}_{2}$; carrot peels; modelling; recovery 


\section{INTRODUCTION}

Due to the increasingly high volumes of waste generated by the food processing industry, developing and establishing waste management practices is paramount. Fruit, vegetables and their by-products are known to contain a variety of valuable compounds including carbohydrates (e.g. dietary fibre, oligosaccharides), aromatic compounds and phytochemicals (e.g., polyphenols, glucosinolates, carotenoids) [1].

Carrots are one of the most consumed vegetables with over 37 million tonnes produced every year worldwide [2]. Such a vast production results in proportionally large amounts of waste, as during carrot processing around $11 \%$ of the initial mass is lost, mainly in the form of peels, tubers and attached flesh. Carrots are enriched with phytochemicals of high importance, such as carotenoids and phenolic compounds [3] that could be extracted and utilised as natural additives (e.g. colourants) for food and pharmaceutical applications. In particular, carotenoids are ubiquitous compounds in vegetables and constitute essential nutrients in the human diet, exerting antioxidant and potentially cancer-preventive properties [4-6].

The extraction of phytochemicals from vegetable matrices is commonly carried out with the aid of conventional chemical solvents, due to their ease of use, efficiency, relatively low cost and wide applicability [7]. The mechanism of extraction rests on the differences in the solubility of the matrix (insoluble residue) and the compounds of interest which, by having high affinity with the liquid solvent phase, promptly diffuse into it. However, conventional solvents require several hours to achieve satisfactory recoveries. Also, the end solutions are often dilute and therefore, an additional concentration step is needed, which could result in degradation or bioactivity losses of the components of interest. In the case of carotenoids, different solvents such as acetone, methanol, hexane and tetrahydrofuran (THF) are commonly used due to the non-polar nature of such phytochemicals [8]. A clear disadvantage is the toxicity of many of these solvents that renders their handling and disposal a hazard for handlers and the environment. 
With the growing environmental concern and the advent of green technologies, new methods for extracting these classes of phytochemicals have been suggested and are currently being studied, including microwave and ultrasound assisted extraction, subcritical water extraction, enzyme-aided extraction and supercritical fluid extraction (SFE) [9-12]. SFE technology employs mainly $\mathrm{CO}_{2}$ and is regarded as a fast, efficient and "clean" method for the extraction of natural products from biomass matrices, such as fruit and vegetables. The extraction of compounds happens similarly to conventional solvents, but fluids in supercritical state possess gas-like properties of diffusion, viscosity and surface tension, as well as liquid-like densities and solvation powers. These properties combined render S$\mathrm{CO}_{2}$ ideal for extracting compounds in a shorter time with higher yields, when compared to conventional liquid-state solvents [13]. Supercritical $\mathrm{CO}_{2}$ results in the recovery of compounds without toxic residues, no degradation of the active components, which can be then recovered in high purity. It is currently used commercially for the decaffeination of coffee and tea [14,15], the extraction of flavours from plant leaves, lipids from milk and fish oils, alcohol from beverages [16] and specialty bioactives for cosmetic applications, such as antiaging creams [13].

The aim of this work was to evaluate the use carrot peels as starting material for the extraction of carotenoids by supercritical $\mathrm{CO}_{2}$. Although previous studies dealing with the extraction of carrot flesh or other vegetable matrices by SFE have been performed [17,18], these were more focused on statistical approach rather than on the variable effects of process kinetics and extract characterisation.

The efficiency of the process was evaluated with respect to global mass yield (\%, ratio between total extracted mass and the amount of initial sample) and carotenoid recovery. A $2^{3}$ Central Composite Design of Experiments (DoE) was carried out to optimise the process conditions and the extraction kinetics, whereas the fit of different models to the data was assessed. Also, experiments using a 10fold initial sample size were performed to attest the scalability potential of the process. Finally, the obtained extracts were compositionally characterised and insights on their potential applications were given. 


\section{MATERIALS AND METHODS}

\subsection{Sample preparation}

Samples of Nantes carrots (Daucus carota) grown in the UK and harvested in February 2015, were purchased from a local supermarket chain in Reading (UK). The carrots were washed and manually peeled. In our experiments, the peels represented $9.5 \%$ of the total vegetable mass loss, a figure quite close the losses occurred during industrial processing of carrots (11\%). The samples of peels and flesh were frozen at $-20{ }^{\circ} \mathrm{C}$ for $36-48 \mathrm{~h}$, freeze dried (VirTis SP Scientific, UK) for $72 \mathrm{~h}$, milled with a grinder and sieved to exclude particles with diameter greater than $750 \mu \mathrm{m}$. The final samples presented a mean particle size of $205 \mu \mathrm{m}$ (70 mesh) for peels and $245 \mu \mathrm{m}$ (60 mesh) for flesh. The samples were then stored in containers away from light and kept at $-20{ }^{\circ} \mathrm{C}$ until further analysis.

\subsection{Total carotenoid content (TCC) determination and identification}

Carotenoids were analysed according to a protocol optimised for carrot matrices [19]. Briefly, 1.0 $2.0 \mathrm{~g}$ of sample were weighed and added into $6 \mathrm{~mL}$ of methanol. After vigorous mixing, samples were centrifuged for 5 min at $2500 \mathrm{x} g$ and the supernatant was separated; a new extraction was performed twice with $8 \mathrm{~mL}$ of a mixture of hexane and acetone (1:1). Subsequently, the organic solvent fractions were combined, $25 \mathrm{~mL}$ of saturated $\mathrm{NaCl}$ were added, and the mixture was shaken in a separator funnel. After phase separation, the lower, water-phase was re-extracted with $8 \mathrm{~mL}$ of hexane and the resulting supernatant was combined with the first. The combined fractions were evaporated under nitrogen stream and re-dissolved in methanol prior to High Pressure Liquid Chromatography (HPLC) analysis. An Agilent Infinity 1260 series HPLC system was used, coupled with a 1260 DAD detector (Agilent Technologies, UK). An YMC-C30 silica-based reversed-phase column (250 x $4.6 \mathrm{~mm}$ ) was used for the separation of carotenoids in a gradient method consisting of (A) methanol/MTBE/water (82:16:2) and (B) methanol/MTBE/water (23:75:2) as mobile phase. The gradient started at $100 \%$ of A. Solvent B was then increased to $50 \%(0-45 \mathrm{~min})$ and further increased to $100 \%$ (46 - $55 \mathrm{~min}$ ), with this condition being held for 5 minutes, totalling 60 min per run. The injection volume was 100 
$\mu \mathrm{L}$ and the flow rate was kept constant at $1.0 \mathrm{~mL} / \mathrm{min}$. For carotenoid identification and quantification, previously-built calibration curves of external commercial standards ( $\alpha$-carotene, $\beta$ carotene and lutein; Sigma-Aldrich) were used. All detected peaks were analysed at $450 \mathrm{~nm}$.

\section{$2.3 \mathrm{~S}-\mathrm{CO}_{2}$ extraction parameters and optimisation of experimental conditions}

Samples of carrot peels were subjected to $\mathrm{S}-\mathrm{CO}_{2}$ extraction in a $\mathrm{S}-\mathrm{CO}_{2}$ rig (SciMed, UK). The apparatus consisted of a recirculating chiller, $\mathrm{CO}_{2}$ line, solvent and co-solvent pumps, heat exchanger, 200-mL extraction vessel, automated backpressure regulator (ABPR), collection vessel and a controlling computer. For every run, $5.0 \mathrm{~g}$ of dried peel samples were thoroughly mixed with $95 \mathrm{~g}$ of inert glass beads (Sigma-Aldrich, UK) to ensure bed homogenisation, placed in the extraction vessel and submitted to a $\mathrm{CO}_{2}$ flow rate of $15 \mathrm{~g} / \mathrm{min}$. Ethanol was used as co-solvent and extraction time was fixed at 80 minutes.

In order to optimise the process, a non-factorial $2^{3}$ Central Composite Design of Experiments (DoE) with three factors at three levels was employed. The three independent variables assessed in the study were temperature $\left(T\right.$, at 50,60 and $\left.70{ }^{\circ} \mathrm{C}\right)$, pressure $(P$, at 150, 250 and 350 bar) and co-solvent concentration $(\mathrm{EtOH}$, at 5, 10 and $15 \% \mathrm{v} / \mathrm{v})$. The dependent variables (or responses) assessed were global mass yield $Y$, defined as the $\%(\mathrm{~g} / \mathrm{g})$ of mass recovered in the extracts with relation to the initial mass load (5.0 g), and total carotenoid content (TCC) recovery $C-R E C$, defined as a percentage (\%, $\mathrm{mg} / \mathrm{mg}$ ) of the initial TCC. Fourteen different experiments including the low, high and axial points of all the parameters were conducted along with a central point replicated three times to calculate experimental errors, totalling 17 runs. At the end of every run, the extracts obtained in ethanol, were evaporated to dryness in a rotavapor (RE 120, Büchi, UK), weighed and re-dissolved in methanol for TCC analysis as described above.

Response Surface Methodology (RSM) was used to represent the model obtained in the form of a 3D graph. All terms in the model equation were tested statistically by the F-test at a $95 \%$ interval of confidence. The values of the determination coefficient $\left(R^{2}\right)$ and the coefficient of variance $(C V, \%)$ 
were also used to confirm the quality of the fitted polynomial model. Lastly, after identifying the critical points by localising the graph global maximum (point where the derivative of the curve is zero), additional triplicate experiments were performed at these critical conditions in order to determine the validity of the optimised conditions. The average values of the experiments were compared to the predicted values given by the model to confirm its accuracy.

\subsection{Extraction kinetics, data modelling and assessment of scalability potential}

Kinetic experiments were also carried out to optimise extraction time, as a function of both global mass yield and carotenoid recovery. The runs were conducted in triplicate at the critical conditions obtained from the DoE study, with all other fixed parameters being kept constant. Extracts were withdrawn every 5 minutes during the first 30 minutes of extraction and every 10 minutes after this point until the end of the run (80 minutes). The Overall Extraction Curves (OECs) for both yield and carotenoid recovery obtained with these studies were fitted to empirical [20,21], desorption [22] and logistic [23] models. Also, in order to assess the influence of higher mass loads on the behaviour of the extraction and how the attained model would respond in larger scales, runs were performed in the SFE using the full capacity of the extraction vessel (50.0 $\mathrm{g}$ of sample) while keeping all other parameters fixed. The extraction time was $210 \mathrm{~min}$ in these cases.

\subsection{Analytical methods}

The extracts of four selected conditions were characterised as to their macronutrient profile (total protein, lipid and carbohydrate content). Total protein content was determined by the Kjeldahl method [24]. The amount of nitrogen and protein present $(\%, w / w)$ was calculated as follows:

$$
\begin{gathered}
\% \text { Nitrogen }=\frac{V_{\mathrm{H} 2 \mathrm{SO} 4}(\mathrm{~mL}) * \mathrm{~N} * 14,007 * 100}{W_{\text {sample }}(m g)} \\
\% \text { Protein }=\% \text { Nitrogen } * 6.25,
\end{gathered}
$$


where $V_{\mathrm{H} 2 \mathrm{SO} 4}$ is the volume $(\mathrm{mL})$ of sulfuric acid $0.1 \mathrm{~N}$ consumed during titration, $N$ is the normality of $\mathrm{H}_{2} \mathrm{SO}_{4}$ and $W_{\text {sample }}$ is the exact weight of the sample submitted to digestion.

The lipid content was determined gravimetrically, using the standard Soxhlet method [25]. Calculation of the lipid content was done by weight difference.

The total carbohydrate content was determined according to the NREL protocol [26]. Approximately $300 \mathrm{mg}$ of sample was submitted to acid hydrolysis with $3 \mathrm{~mL}$ of $\mathrm{H}_{2} \mathrm{SO}_{4}(72 \%$, v/v) followed by incubation at $30{ }^{\circ} \mathrm{C}$ for $1 \mathrm{~h}$. The liquid phase was then diluted to $3 \% \mathrm{H}_{2} \mathrm{SO}_{4}(\mathrm{v} / \mathrm{v})$ and autoclaved at $121{ }^{\circ} \mathrm{C}$ for $30 \mathrm{~min}$. After cooling down, the $\mathrm{pH}$ value of the supernatants was adjusted to 5.0 using $\mathrm{CaCO}_{3}$ and the supernatants were filtered and subject to analysis in a HPLC system coupled with DAD/RI detectors (Agilent Infinity, 1260 series). The column used was an Aminex HPX-87H (300 x $7.8 \mathrm{~mm}$ ), the isocratic mobile phase employed was $0.005 \mathrm{M} \mathrm{H}_{2} \mathrm{SO}_{4}$ and the flow rate was $0.6 \mathrm{~mL} / \mathrm{min}$. The injection volume was $20 \mu \mathrm{L}$ and the quantification of sugars was performed with the aid of previously-plotted calibration curves of external individual standards of glucose, fructose, xylose, arabinose and galacturonic acid (Sigma-Aldrich).

\section{RESULTS AND DISCUSSION}

\subsection{Carotenoid content of carrot samples}

The individual carotenoids identified and their concentrations, along with the total carotenoid content (TCC) in the samples of carrot flesh and peels are presented in Table 1.The TCC in carrots can vary from 4.6 to $548 \mu \mathrm{g} / \mathrm{g}$, depending on the different cultivars [27-30].

The results obtained in the current study are within the range of values reported in the literature. $\beta$ Carotene was identified as the main carotenoid in the samples, representing around $60 \%$ of the TCC in both flesh and peel, followed by $\alpha$-carotene, making up for around $30 \%$ of the TCC in both samples. In the peels, these two carotenoids accounted for approximately 95\% of TCC. Other carotenoids identified were lycopene and lutein, but were present in much lower concentrations (1.9$30.2 \mu \mathrm{g} / \mathrm{g})$. 
It is noted that a considerably high TCC was present in the peels, which amounted to around $60 \%$ of that in the flesh. It is likely that a considerable part of the high TCC found in peels is due to the flesh still attached to them after the peeling process. This highlights the potential of using this particular byproduct for the recovery of carotenoids.

\subsection{Optimisation of $\mathrm{S}-\mathrm{CO}_{2}$ extraction of carotenoids}

Dried carrot peels were subjected to $\mathrm{S}-\mathrm{CO}_{2}$, targeting the recovery of carotenoids. Table 2 shows the values obtained for both mass yield and carotenoid recovery, under the 17 conditions assessed, according to the non-factorial Central Composite Design of Experiments (DoE). The presence of values outside the fixed limits (runs 9-14), is a characteristic inherent in the CCD and is useful for observing the behaviour of regions out of the chosen range, as it can indicate a trend in case the critical points are spotted outside these boundaries. A few studies in the literature using different raw materials have employed conditions other than those proposed in this study, with pressures as low as 100 bar and as high as 500 bar and temperatures varying from 40 to $90{ }^{\circ} \mathrm{C}$ [31-36]. Although in theory, the nonpolar nature of carotenoids should allow their extraction in $\mathrm{SC}-\mathrm{CO}_{2}$ without the addition of a modifier, preliminary studies (data not shown) revealed that the exclusion of a cosolvent from the extraction process resulted in carotenoid recoveries of no greater than $34 \%(\mathrm{w} / \mathrm{w})$, mainly due to the high molecular weight of the targeted compounds. Besides, preliminary studies showed that the use of ethanol resulted into better carotenoid recoveries compared to methanol (data not shown). By taking also into account its low toxicity, it was decided to utilise ethanol as a cosolvent for all experiments.

There was a considerable variation in the mass yield and total carotenoid recovery values for the different conditions assessed, which highlights the high relevance of this statistical process optimisation study. In terms of the response tested, the global mass yield ranged from $0.31 \%$ (run 5) to $5.70 \%$ (run 14) and the C-REC from $34.9 \%$ (run 1) to $82.5 \%$ (run 14 ). 
Figure 1 depicts the Pareto Charts of Effects, which demonstrate the influence of the variables and their interactions on global mass yield and carotenoid recovery (at a 95\% level of significance). All variables that surpassed the line at $p=5 \%$ were deemed to have affected significantly the mass yield or the recovery of carotenoids, respectively.

With regards to mass yield, it can be observed that only the linear term of co-solvent concentration affected significantly the extraction, while none of the quadratic terms or the interactions of the linear terms showed a significant effect $(p>0.05)$. Ethanol is highly efficient in increasing the polarity of $\mathrm{CO}_{2}$, allowing the dissolution of polar macronutrients, e.g. carbohydrates and amphipathic lipids or proteins. This can explain the higher mass yields that were obtained as ethanol levels increased. Both the quadratic term of the co-solvent concentration and the temperature did influence the extraction at 94.6 and $94.4 \%$ of significance, respectively. Although not crossing the 95\%-level threshold set for the experiments, these parameters are certainly important, as they can affect the process to an extent.

With regards to carotenoid recovery, all linear variables presented a statistically significant influence, with pressure imposing the greatest effect on the process. Pressure, in conjunction with temperature, plays a major role in increasing the solvation power of $\mathrm{CO}_{2}$, favouring the extraction of micronutrients, and effectively phytochemicals. Although a temperature increase showed a clear effect on carotenoid yield in $\mathrm{S}-\mathrm{CO}_{2}$, pressure is the factor that mostly influenced carotenoid recovery, since carotenoids are large molecules and their vapour pressure is low [37]. Additionally, higher pressures are believed to disrupt the vegetable cell walls and other stronger chemical interactions between different compounds (lipids, carbohydrates) and the vegetable cell wall structures, which can cause carotenoids to dissociate from these structures and hence, to be more easily expelled from the extraction bed [38]. Higher co-solvent concentrations also resulted in positive influences in the process. Although carotenoids usually present very low polarity, they are high-molecular-weight molecules and the presence of an entrainer (e.g. ethanol, methanol, etc.) facilitates their extraction, since it can aid the dissolution of heavier substances in $\mathrm{CO}_{2}$. Also, by observing both linear and quadratic temperature effects on the graph, it can be noted that temperature had a dual behaviour: increasing the temperature had a positive influence on the process (linear term) but very high 
temperatures affected the extraction negatively (quadratic term). This is advantageous not only from an economical point of view, but it is also a qualitative benefit, since high temperatures can lead to carotenoid degradation and isomerisation [37], compromising their stability and bioactivity. Additionally, quadratic pressure was also found to be statistically significant to the model.

Besides identifying the optimal conditions, another important function of the models is the fact that once statistically validated, they enable the prediction of the response variables (mass yield or carotenoid recovery), given any conditions within the studied range.

For mass yield (\%) the equation is:

$[\mathrm{Y}] \%=0.87887 *[\mathrm{~T}]-0.0075781 *[\mathrm{~T}]^{2}+0.84782 *[\mathrm{CS}]-0.030666 *[\mathrm{CS}]^{2}+0.0001025 *$ $[\mathrm{T}] *[\mathrm{P}]-0.00155 *[\mathrm{~T}] *[\mathrm{CS}]+0.000395 *[\mathrm{P}] *[\mathrm{CS}]-28.2153 \quad$ (Eq. 1), where $[\mathrm{Y}]=$ yield; $[\mathrm{T}]=$ temperature $\left({ }^{\circ} \mathrm{C}\right) ;[\mathrm{CS}]=$ co-solvent concentration $(\%) ;[\mathrm{P}]=$ pressure $($ bar $)$.

For carotenoid recovery $(\%)$ the equation is:

$$
\begin{aligned}
& {\left[\mathrm{C} \_ \text {REC }\right] \%=10.17256 *[\mathrm{~T}]-0.06667 *[\mathrm{~T}]^{2}+7.16074 *[\mathrm{CS}]-0.17624 *[\mathrm{CS}]^{2}-0.004255 *} \\
& {[\mathrm{~T}] *[\mathrm{P}]-0.052695 *[\mathrm{~T}] *[\mathrm{CS}]+0.004158 *[\mathrm{P}] *[\mathrm{CS}]-237.1932(\text { Eq. } 2),}
\end{aligned}
$$

where $[\mathrm{Y}]=$ yield; $[\mathrm{T}]=$ temperature $\left({ }^{\circ} \mathrm{C}\right) ;[\mathrm{CS}]=$ co-solvent concentration $(\%) ;[\mathrm{P}]=$ pressure $(\mathrm{bar})$.

In order to confirm the adequacy of the model, an analysis of variance (ANOVA) was performed along with an F-test (lack of fit), for validation. For mass yield, the $\mathrm{R}^{2}$-value was 0.808 and that the Fvalue (3.06) was higher than the tabulated $F$ value $\left(F_{9,7}=2.72\right)$. For carotenoid recovery, the $R^{2}$-value was of 0.870 and the F-experimental value (5.26) was almost twice the F-tabulated value $\left(\mathrm{F}_{9,7}=2.72\right)$. Hence, for both cases, it can be deduced that the models can satisfactorily describe the extraction process. 
The conditions for maximising the responses were identified by determining the absolute maxima of the response surface graphs generated (Figures 2a and b). For global mass yield, these conditions were: temperature of $58.5^{\circ} \mathrm{C}$, pressure of $306 \mathrm{bar}$ and at $14.3 \%(\mathrm{v} / \mathrm{v})$ of co-solvent. This set of values predicted an extract mass of $5.31 \%(\mathrm{w} / \mathrm{w})$. The maximum carotenoid recovery $(86.1 \%)$, in turn, was found at $59.0{ }^{\circ} \mathrm{C}, 349$ bar and with the aid of $15.5 \%$ of co-solvent, conditions very similar to those for mass yield. The critical points were then tested by performing three experiments under the critical conditions and comparing these to the predicted results. A low variance of the experimental values (5.38\% of mass and $87.0 \%$ of carotenoid recovery) with the predicted responses was found. The models are very consistent and therefore valid to describe the whole process.

Table 3 presents a list of studies that involved the optimisation of the extraction via $\mathrm{S}-\mathrm{CO}_{2}$ of different food materials (for global mass and carotenoid recovery), with the key variables influencing the process and the recovery values for each material.

Based on literature findings, pressure is the mostly reported parameter that influences the mass yield of solid biomass residues extracted under SFE process. The ranges tested in these studies are usually between $200-450$ bar. Temperature has also been shown to affect the extraction in most of the processes, particularly in the range of $50-70{ }^{\circ} \mathrm{C}$. Exceptions to this are banana peels [39] and pomegranate seeds [47], where temperature does not have a statistically significant effect on the process. Co-solvent concentration has only been investigated for grape peels [40] and tomato peels [49], and in both cases there was no significant effect on extraction. Other factors that have been reported to play significant roles are extraction time and $\mathrm{CO}_{2}$ flow rate. In terms of the raw materials used, not many studies have focused on the use of by-products/solid residues for SFE. In the case of peels specifically, only banana, grape, mango and tomato have been investigated, and therefore a more comprehensive comparison with literature data is hindered.

With regards to the results of the current study, carrot peels generated a lower amount of extracted mass compared to banana (6.9\%) and grape (13.2\%). One explanation for that might lie in the different composition of these matrices, the nature and amount of their components (carbohydrates, proteins, lipids, etc.) and the strength of the interactions between these and the vegetable structures. 
Dietary fibre is abundant in carrots, with around $88 \%$ of the vegetable being composed of cellulose and hemicellulose, and both of them constitute materials with rigid structures [56]. The latter is further reinforced by the fact that in the case of mango peels, which are abundant in lignin, even lower mass yields (3.15\%) [43] than carrots were reported. The fact that only the co-solvent concentration was shown to significantly affect the extraction of mass from carrot peels (while for banana and grape, pressure and temperature were the most influential parameters) indicates that for food matrices that have high cellulose content, the amount of entrainer is potentially more important than the temperature $v s$. pressure binomial. A noteworthy point, however, is the fact that the global mass yield is only one of the indicators for assessing the effectiveness of extraction. When the raw material is a medicinal plant or food, the most important factor for the selection of an extraction technique is the profile of the extract obtained and the amount of the bioactive compounds present [57]. In many cases, depending on the application, lower mass extracts may be advantageous as this can minimise the need for further downstream unit operations.

On the other hand, for carotenoid recovery (Table 3), almost all studies confirm the influence of temperature, pressure and co-solvent on the extraction, with the exception of tomato skin and watermelon. The highest carotenoid recovery (86\%) was observed for paprika samples, a value identical to that obtained in this work. High recoveries were also achieved for tomato juice, pumpkin and citrus press cake (77, 76 and $73 \%$, respectively). This indicates that the conditions obtained in this work can ensure very high recoveries of carotenoid fractions with a low level of extracted mass and could potentially be applied to other vegetable waste matrices as well.

\subsection{Kinetic experiments and data modelling}

Figures $3 \mathrm{a}$ and $3 \mathrm{~b}$ show the kinetic profiles (Overall Extraction Curves, OEC) of the experiments carried out under the optimised conditions fitted with the Naik, Esquivel, Martínez and Tan and Liou models. 
Sovová [58] presented an interesting approach for classifying the stages of the kinetics of the OECs when working with supercritical fluid extractions. The samples used in the process were initially dried and milled to reduce particle size, promoting higher extraction rates in the first few minutes due to fact that the compounds of interest had been exposed in the surface of the "broken cells". In CER (Constant Extraction Rate) stage, solute dissolution in the solvent is facilitated and convection is the main mass transfer mechanism from the solid to the fluid phase. The process then enters the FER (Falling Extraction Rate) stage due to the exhaustion of the free solute in the cell surface, with the "intact cells", i.e. cells not broken by the milling process, still having their compounds segregated within. This slows down the extraction rate (curved line) and makes the extraction of the compounds more difficult. In FER, mass transfer happens by both convection and diffusion. When all the easily extractable solute is exhausted, the extraction rate can be seen as an almost-straight line, with a very low slope, and mass transfer can occur only by effective diffusion of the solute from the solid particles to the $\mathrm{CO}_{2}$, hence this stage being known as DC (Diffusion Controlled).

Based on Figure 3a, it can be stated that the global mass extraction rate was high in the first minutes (50\% of the yield was reached at $11 \mathrm{~min}$ and $75 \%$ by $25 \mathrm{~min}$ ) and started to decrease due to the exhaustion of the free solute as the process progressed, leading the extraction to enter the FER phase after 17 minutes. The optimum time for this extraction was found to be between 40 and 50 min (just after the beginning of DC stage, when $90 \%$ and $95 \%$ of the extractable mass had already been recovered). A 5\% increase in the yield is not enough to justify extending the extraction, as this would require additional solvent, energy and processing time.

For carotenoids (Figure 3b), the extraction rate in the first moments of the extraction is visibly higher than that for yield, given the very steep slope observed in the CER phase, which lasted for just 6 minutes. After only $5 \mathrm{~min}, 65 \%$ of all the extractable carotenoids had already been recovered. This value increased to $88 \%$ after $15 \mathrm{~min}$ and to about $97 \%$ by $30 \mathrm{~min}$ (when the total recovery had reached $87.0 \%$ ). The process can be interrupted at this point, since extending it for a further $50 \mathrm{~min}$ does not justify the recovery of the remaining 3\%. Moreover, longer extraction times can lead to decreased carotenoid recovery, possibly due to heat degradation within the extraction vessel $[59,60]$. 
It can be assumed that with the milling process, the carotenoids are exposed in the surface of the solid particles and therefore their dissolution in $\mathrm{CO}_{2}$ occurs in fact mostly by convection, fomenting the very fast extraction rate observed in the early stages of the kinetic experiments.

Table 4 presents the adjustable parameters used to fit the four models.

The models of Naik [21] and Esquível [20] are classified as empirical models. They rely on the nonlinear shape of the OEC and hence use appropriate functions to fit the data. As observed in Fig. 3 and in Table 4, Naik's and Esquível's models describe the extraction kinetics very well, given the high $\mathrm{R}^{2}$ values and the low errors for both yield and carotenoids. The disadvantage of these models, however, is that some of the adjustable parameters $\left(\mathrm{B}_{1 \mathrm{E}}\right.$ and $\mathrm{C}_{1}$, respectively) have no practical physical meaning and, despite the very good fit, the models deliver very little information that can be of use for further studies.

The model of Martínez [23] (logistic model) assumes that the extract is a mixture of compounds or group of compounds with similar chemical structures and introduces the parameter $t_{m}$, defined as the time when the extraction reaches its maximum rate, which can be a useful indicator for controlling the process. Having a $t_{m}$ of $4.3 \mathrm{~min}$ in the Martinez's model confirms the very fast extraction trends for TCC, compared with the mass yield experiments, which had a $t_{m}$ of $14.9 \mathrm{~min}$. The high $\mathrm{R}^{2}(0.92 \mathrm{in}$ both graphs) demonstrated a good fit, although not the best among the models.

Tan and Liou's model (desorption model) [22] uses analogies to the adsorption phenomena and takes into account that the solutes dissolve in the solvent following a desorption process in the solid particles. The desorption (or distribution constant) coefficient $K_{d}$ indicates how strong the compounds are adsorbed to the solid phase: the lower the value, the stronger the interactions between the solute and the particles surface and consequently, the more difficult their extraction. $K_{d}$ values between $10^{-2}$ and $10^{-3}$, such as those found for global yield, indicate a slow desorbing fraction [61], thus requiring more contact time to recover all the extractable material. This reinforces the theory that macroextractants, such as carbohydrates or lipids, are more strongly-bound to the carrot peel structures. The $K_{d}$ constant is almost 5-fold higher for carotenoids than it is for mass yield, confirming that the 
carotenoids are easily disposed in the sample matrix. This is a strong indication that with grinding, carotenoids are exposed at the outermost layers of the particles and mass transfer is therefore favoured, since an extraction with a $K_{d}$ value of 0.185 can be considered as fast [61].

The models of Naik, Esquível and Tan and Liou can be employed to describe the process with confidence, given the high $\mathrm{R}^{2}$-values and low errors presented. In general, it can be observed that the experimental kinetics for C-REC fits the models proposed slightly better than mass yield does.

\subsection{Assessment of scalability potential}

Various scale-up routes for SFE (and other extraction processes) have been reported and suggested in the scientific literature. However, a general consensus on the key criteria for scaling-up procedures has not been reached yet [62]. The most commonly used procedures involve maintaining constant: (1) the solvent mass to sample mass ratio, (2) the flow rate to sample mass ratio, (3) both aforementioned conditions along with a dimensionless number, e.g., $R e$ [10]. Due to equipment and process limitations, none of these approaches could be applied in the present study, as this would involve changing extractor dimensions and/or sample particle size. Therefore, it was decided to keep all the optimised conditions constant and increase solely the sample mass. It is envisaged that this approach would still provide useful information of the extraction behaviour under the optimised conditions on a more real-scale application. To this end, a 210-minute triplicate run under the best conditions was performed, in which the mass load was increased by 10 -fold (from $5.0 \mathrm{~g}$ to $50.0 \mathrm{~g}$ ) in the absence of glass beads. As emphasised, all other parameters were kept constant. The averaged data (in \%) were plotted against time, along with data obtained in the previous experiments, and are depicted in Fig. 4.

When the mass load was increased from $5.0 \mathrm{~g}$ to $50.0 \mathrm{~g}$, the global yield decreased from $5.38 \%$ to 2.09\%. Increasing the sample mass affected positively the carotenoid recovery, which reached $96.2 \%$ in the full-vessel run, with a total of $9.89 \mathrm{mg}$ of carotenoids being extracted. As expected, the CER phase lasted longer in this experiment $(27 \mathrm{~min})$ than in the previous $(6 \mathrm{~min})$. This was due to the fact 
that the $\mathrm{CO}_{2}$ flow rate was kept constant while the mass was increased. The scaled-up experiment reached the same $87 \%$-recovery mark attained in the small-scale experiment (Fig. 3b) at around 115 min and then proceeded to reach its plateau (96.2\%) at the 180-min mark, which was the optimum time for this process.

A considerable decrease of the extracted mass was noted, whereas at the same time, carotenoid recovery was found to increase. This observation is most likely to occur due to the longer residence time of the $\mathrm{CO}_{2}$ in the extraction bed and to a higher selectivity exhibited by the solvent. In the first experiment, the vessel had a 6-cm extraction height (sample plus glass beads), while in the second, the full vessel $(15 \mathrm{~cm})$ was loaded with sample. In this scenario, the bed presented a much lower porosity with almost no head-space, the fluid had more pathways to flow through, ensuring a higher contact time between the phases, less pronounced dispersion effects, faster saturation of the $\mathrm{CO}_{2}$ with the compounds of interest and consequently, more effective mass transfer rates. Additionally, an increase in selectivity could be taking place due to the presence of higher sample mass, since by applying the same flow rate, the fluid saturated preferentially with the carotenoids that were present in abundance within the full capacity vessel and much less with more polar macro-compounds, such as carbohydrates.

\subsection{Compositional analysis of extracts}

Different combinations of high and low $P, T$ and co-solvent concentrations during $\mathrm{S}-\mathrm{CO}_{2}$ extraction can result in distinct extract profiles. Table 5 shows the mass of the final extracts, their composition breakdown in percentage of individual macronutrients $(\% E X T)$, as well as the amount recovered for each component from the original carrot peel samples in d.b. (\% REC) under each of the four tested conditions.

Extract 1 represented the optimal conditions, as attained by the DoE studies, and exhibited the highest amount of carbohydrates among all runs (57.6\%), as well as the highest recovery of carbohydrates (25\%). This is due to the relatively high percentage of ethanol used as modifier (18.4\%), which added 
polarity to the $\mathrm{CO}_{2}$ and resulted in the extraction of very polar compounds, such as carbohydrates. This reflects on the total extracted mass $(216.5 \mathrm{mg})$, which was around 4-fold higher than those obtained in all other conditions. As a consequence of the increased polarity, lipids - highly nonpolar compounds - were present at the lowest amounts among the runs, making up only $12 \%$ of this particular extract. The opposite was observed in extract 2, where no co-solvent was used. The amount of extracted mass $(58.1 \mathrm{mg}$ ) was the lowest observed, with $62 \%$ of it consisting of lipids and only $17 \%$ of carbohydrates.

Extracts 3 and 4 represented intermediate conditions of $T, P$ and $E t O H \%$. Specifically, extract 3 (low pressure, low temperature) yielded the highest protein amount (22.5\%), even though protein values did not change dramatically among runs. Another noteworthy observation is that extract, despite the much lower values of $P, T$ and $E t O H \%$ employed compared to the optimal extraction conditions (extract 1), contained very similar amounts of total carbohydrates as in extract 1. Also, when comparing extracts 3 and 4 (high pressure, high temperature and slightly less $\mathrm{EtOH} \%$ ), it can be noticed that the carbohydrate content decreased considerably, which seems to indicate that carbohydrates are much more sensitive to changes in co-solvent concentrations than in pressure or temperature, i.e., in the solvation power of $\mathrm{CO}_{2}$.

Although the carbohydrate content varied among extracts, HPLC analysis showed that the sugar profile of the extracts did not change considerably. All extracts were composed of around 50-55\% glucose (deriving mainly from beta-glucans and hemicelluloses and to a lesser extent, from cellulose), $24-26 \%$ of galacturonic acid (from pectins), $19-21 \%$ of xylose and $7 \%$ of arabinose, both from arabinoxylans.

Based on their composition and depending on the desired final application, these extracts could be potentially utilised directly as ingredients for food (as natural food colourants or processing ingredients) or animal feed applications (animal feed ingredients). Moreover, additional downstream operations could be performed, in cases where a considerably higher purity of carotenoids is required (e.g. employment as fine supplements or as additives in cosmetic and pharmaceutical formulations, etc.). Potential methodologies that could be applied to the $\mathrm{SC}-\mathrm{CO}_{2}$ extracts to obtain carotenoids in a 
purer form include conventional solvent extraction, adsorption with hydrophobic interaction resins and ultrafiltration. Such processes would constitute promising alternatives to the chemical synthesis route that is currently used for the production of commercial carotenoids [63]. In addition, a number of applications could be further investigated for the solid residues left after the $\mathrm{S}-\mathrm{CO}_{2}$ extraction process. In our study, it was found that the majority of macronutrients present in the original carrot peel samples, i.e. proteins, carbohydrates and lipids, remained intact within the residual mass. As a consequence, the carotenoid-free residue could be used as starting material for the extraction of those macronutrients, which could be used as natural emulsifiers and stabilisers or transformed via fermentation to biofuels and platform chemicals.

\section{CONCLUSIONS}

The results presented in this study allowed a thorough assessment of the direct influence of process variables on supercritical $\mathrm{CO}_{2}$ extraction of carotenoids from carrot peels, which enabled its statistical and kinetic modelling, and the assessment of its scalability potential and extract characterisation. The best extraction conditions resulted in a $96.2 \%$ of carotenoid recovery, when using the full capacity of the extraction vessel. The kinetic studies demonstrated that supercritical $\mathrm{CO}_{2}$ can extract carotenoid fractions from carrot peels rapidly, whereas model fitting highlighted the fast extraction trend and desorbing nature of carotenoids, based on the values obtained for the model parameters. The findings of the current study could be applied for other vegetable by-product matrices with similar structure, targeting the extraction of carotenoids. 


\section{ACKNOWLEDGEMENTS}

The authors would like to acknowledge CAPES - Coordination for the Improvement of Higher Education Personnel (Brasilia - Brazil) [Grant number: 99999.011894/2013-00] for their financial support on the study. 


\section{REFERENCES}

[1] K. Waldron, Handbook of waste management and co-product recovery in food processing (v.1), CRC Press - Woodhead Publishing Limited, Cambridge, England, 2007.

[2] FAOSTAT, Food and Agriculture Organization of the United Nations, FAOSTAT Stat. Database. (2013).

[3] W. Stahl, H. Sies, Bioactivity and protective effects of natural carotenoids, Biochim. Biophys. Acta - Mol. Basis Dis. 1740 (2005) 101-107. doi:10.1016/j.bbadis.2004.12.006.

[4] K.H. Cha, S.Y. Koo, D.-U. Lee, Antiproliferative Effects of Carotenoids Extracted from Chlorella ellipsoidea and Chlorella vulgaris on, J. Agric. Food Chem. (2008) 10521-10526.

[5] G. Maiani, M.J.P. Castón, G. Catasta, E. Toti, I.G. Cambrodón, A. Bysted, F. GranadoLorencio, B. Olmedilla-Alonso, P. Knuthsen, M. Valoti, V. Böhm, E. Mayer-Miebach, D. Behsnilian, U. Schlemmer, Carotenoids: actual knowledge on food sources, intakes, stability and bioavailability and their protective role in humans., Mol. Nutr. Food Res. 53 Suppl 2 (2009) S194-218. doi:10.1002/mnfr.200800053.

[6] R. Pangestuti, S.-K. Kim, Biological activities and health benefit effects of natural pigments derived from marine algae, J. Funct. Foods. 3 (2011) 255-266. doi:10.1016/j.jff.2011.07.001.

[7] J. Dai, R.J. Mumper, Plant phenolics: extraction, analysis and their antioxidant and anticancer properties., Molecules. 15 (2010) 7313-52. doi:10.3390/molecules15107313.

[8] D.B. Rodriguez-Amaya, M. Kimura, HarvestPlus Handbook for Carotenoid Analysis, HarvestPlus Technical Monographs, Washington, DC, 2004.

[9] B. a Acosta-Estrada, J. a Gutiérrez-Uribe, S.O. Serna-Saldívar, Bound phenolics in foods, a review., Food Chem. 152 (2014) 46-55. doi:10.1016/j.foodchem.2013.11.093.

[10] M.M.R. de Melo, a. J.D. Silvestre, C.M. Silva, Supercritical fluid extraction of vegetable matrices: Applications, trends and future perspectives of a convincing green technology, J. Supercrit. Fluids. 92 (2014) 115-176. doi:10.1016/j.supflu.2014.04.007.

[11] M. Herrero, a Cifuentes, E. Ibanez, Sub- and supercritical fluid extraction of functional ingredients from different natural sources: Plants, food-by-products, algae and microalgaeA review, Food Chem. 98 (2006) 136-148. doi:10.1016/j.foodchem.2005.05.058.

[12] T.C. Kha, H. Phan-Tai, M.H. Nguyen, Effects of pre-treatments on the yield and carotenoid content of Gac oil using supercritical carbon dioxide extraction, J. Food Eng. 120 (2014) 4449. doi:10.1016/j.jfoodeng.2013.07.018.

[13] J. Azmir, I.S.M. Zaidul, M.M. Rahman, K.M. Sharif, a. Mohamed, F. Sahena, M.H. a. Jahurul, K. Ghafoor, N. a. N. Norulaini, a. K.M. Omar, Techniques for extraction of bioactive compounds from plant materials: A review, J. Food Eng. 117 (2013) 426-436. doi:10.1016/j.jfoodeng.2013.01.014.

[14] H. Park, H. Lee, M. Shin, K. Lee, Y. Kim, K. Kim, Effects of cosolvents on the decaffeination of green tea by supercritical carbon dioxide, Food Chem. 105 (2007) 1011-1017. doi:10.1016/j.foodchem.2007.04.064.

[15] J. Tello, M. Viguera, L. Calvo, Extraction of caffeine from Robusta coffee (Coffea canephora var. Robusta) husks using supercritical carbon dioxide, J. Supercrit. Fluids. 59 (2011) 53-60. doi:10.1016/j.supflu.2011.07.018.

[16] G. Brunner, Supercritical fluids: technology and application to food processing, J. Food Eng. 67 (2005) 21-33. doi:10.1016/j.jfoodeng.2004.05.060.

[17] P.J. Vega, M.O. Balaban, C.A. Sims, S.F. O'Keefe, J.A. Cornell, Supercritical Carbon Dioxide Extraction Efficiency for Carotenes from Carrots by RSM, J. Food Sci. 61 (1996).

[18] M.M. Barth, C. Zhou, K.M. Kute, G. a Rosenthals, Extraction of Carotenoids from Carrot 
(Daucus carota L.) Tissue, J. Agric. Food Chem. 43 (1995) 2876-2878.

doi:10.1021/jf00059a019.

[19] E. Biehler, F. Mayer, L. Hoffmann, E. Krause, T. Bohn, Comparison of 3 Spectrophotometric Methods for Carotenoid Determination in Frequently, J. Food Sci. (2009). doi:10.1111/j.17503841.2009.01417.x.

[20] M.M. Esquivel, M.G. Bernardo-gil, M.B. King, Mathematical models for supercritical extraction of olive husk oil, J. Supercrit. Fluids. 16 (1999) 43-58.

[21] S.N. Naik, H. Lentz, R.C. Maheshwari, Extraction of Perfumes and flavours from plant materials with liquid carbon dioxide under liquid-vapor equilibrium conditions, Fluid Phase Equilib. 49 (1989) 115-126.

[22] C.S. Tan, D.C. Liou, Modeling of desorption at supercritical conditions, AIChE J. 35 (1989) $1029-1031$.

[23] J. Martínez, A.R. Monteiro, P.T. V Rosa, M.O.M. Marques, M.A.A. Meireles, Multicomponent Model To Describe Extraction of Ginger Oleoresin with Supercritical Carbon Dioxide, Ind. Eng. Chem. Res. (2003) 1057-1063.

[24] AOAC, Official Methods of Analysis of AOAC INTERNATIONAL, Gaithersburg, Maryland, USA, 1995.

[25] AOAC, Official Methods of Analysis of AOAC INTERNATIONAL, Gaithersburg, Maryland, USA, 1980.

[26] A. Sluiter, Determination of Sugars, Byproducts, and Degradation Products in Liquid Fraction Process Samples, in: Natl. Renew. Energy Lab., 2011.

[27] J. Grassmann, W.H. Schnitzler, R. Habegger, Evaluation of different coloured carrot cultivars on antioxidative capacity based on their carotenoid and phenolic contents., Int. J. Food Sci. Nutr. 58 (2007) 603-11. doi:10.1080/09637480701359149.

[28] A. Mech-nowak, A. Świderski, M. Kruczek, I. Łuczak, A. Kostecka-gugała, Content of carotenoids in roots of seventeen cultivars of Daucus carota L ., Acta Biochim. Pol. 59 (2012) $139-142$.

[29] C. Nicolle, E. Rock, P. Amouroux, C. Rémésy, Genetic Variability Influences Carotenoid, Vitamin, Phenolic, and Mineral Content in White, Yellow, Purple, Orange, and Dark-orange Carrot Cultivars, J. Am. Soc. Hortic. Sci. 129 (2004) 523-529.

[30] R.L. Surles, N. Weng, P.W. Simon, S.A. Tanumihardjo, Carotenoid Profiles and Consumer Sensory Evaluation of Specialty Carrots (Daucus carota, L.) of Various Colors, J. Agric. Food Chem. 52 (2004) 3417-3421.

[31] O. Döker, U. Salgın, İ. Şanal, Ü. Mehmetoğlu, a. Çalımlı, Modeling of extraction of $\beta$ carotene from apricot bagasse using supercritical $\mathrm{CO} 2$ in packed bed extractor, J. Supercrit. Fluids. 28 (2004) 11-19. doi:10.1016/S0896-8446(03)00006-8.

[32] J. a. Egydio, A.M. Moraes, P.T. V Rosa, Supercritical fluid extraction of lycopene from tomato juice and characterization of its antioxidation activity, J. Supercrit. Fluids. 54 (2010) 159-164. doi:10.1016/j.supflu.2010.04.009.

[33] G.L. Filho, V. V. De Rosso, M.A. a. Meireles, P.T.V. Rosa, A.L. Oliveira, A.Z. Mercadante, F. a. Cabral, Supercritical CO2 extraction of carotenoids from pitanga fruits (Eugenia uniflora L.), J. Supercrit. Fluids. 46 (2008) 33-39. doi:10.1016/j.supflu.2008.02.014.

[34] L.S.V. Katherine, C.C. Edgar, W.K. Jerry, R.H. Luke, C.D. Julie, Extraction conditions affecting supercritical fluid extraction (SFE) of lycopene from watermelon., Bioresour. Technol. 99 (2008) 7835-41. doi:10.1016/j.biortech.2008.01.082.

[35] N. Mezzomo, J. Martínez, M. Maraschin, S.R.S. Ferreira, Pink shrimp (P. brasiliensis and P. paulensis) residue: Supercritical fluid extraction of carotenoid fraction, J. Supercrit. Fluids. 74 (2013) 22-33. doi:10.1016/j.supflu.2012.11.020. 
[36] J. Shi, C. Yi, X. Ye, S. Xue, Y. Jiang, Y. Ma, D. Liu, Effects of supercritical CO2 fluid parameters on chemical composition and yield of carotenoids extracted from pumpkin, LWT Food Sci. Technol. 43 (2010) 39-44. doi:10.1016/j.lwt.2009.07.003.

[37] J.M. Prado, P.C. Veggi, M.A. a. Meireles, Extraction Methods for Obtaining Carotenoids from Vegetables - Review, Curr. Anal. Chem. 10 (2014) 29-66. doi:10.2174/1573411011410010005.

[38] M. Khajeh, Optimization of process variables for essential oil components from Satureja hortensis by supercritical fluid extraction using Box-Behnken experimental design, J. Supercrit. Fluids. 55 (2011) 944-948. doi:10.1016/j.supflu.2010.10.017.

[39] S.R.R. Comim, K. Madella, J.V. Oliveira, S.R.S. Ferreira, Supercritical fluid extraction from dried banana peel (Musa spp., genomic group AAB): Extraction yield, mathematical modeling, economical analysis and phase equilibria, J. Supercrit. Fluids. 54 (2010) 30-37. doi:10.1016/j.supflu.2010.03.010.

[40] K. Ghafoor, J. Park, Y.-H. Choi, Optimization of supercritical fluid extraction of bioactive compounds from grape (Vitis labrusca B.) peel by using response surface methodology, Innov. Food Sci. Emerg. Technol. 11 (2010) 485-490. doi:10.1016/j.ifset.2010.01.013.

[41] K. Ghafoor, F.Y. Al-Juhaimi, Y.H. Choi, Supercritical fluid extraction of phenolic compounds and antioxidants from grape (Vitis labrusca B.) seeds., Plant Foods Hum. Nutr. 67 (2012) 40714. doi:10.1007/s11130-012-0313-1.

[42] H.I. Castro-Vargas, L.I. Rodríguez-Varela, S.R.S. Ferreira, F. Parada-Alfonso, Extraction of phenolic fraction from guava seeds (Psidium guajava L.) using supercritical carbon dioxide and co-solvents, J. Supercrit. Fluids. 51 (2010) 319-324. doi:10.1016/j.supflu.2009.10.012.

[43] M.P. Garcia-Mendoza, J.T. Paula, L.C. Paviani, F.A. Cabral, H.A. Martinez-Correa, Extracts from mango peel by-product obtained by supercritical $\mathrm{CO} 2$ and pressurized solvent processes, LWT - Food Sci. Technol. 62 (2015) 131-137. doi:10.1016/j.lwt.2015.01.026.

[44] G. Zahedi, A. Azarpour, Optimization of supercritical carbon dioxide extraction of Passiflora seed oil, J. Supercrit. Fluids. 58 (2011) 40-48. doi:10.1016/j.supflu.2011.04.013.

[45] J. Viganó, J.P. Coutinho, D.S. Souza, N.A.F. Baroni, H.T. Godoy, J.A. Macedo, J. Martínez, Exploring the selectivity of supercritical $\mathrm{CO} 2$ to obtain nonpolar fractions of passion fruit bagasse extracts, J. Supercrit. Fluids. 110 (2016) 1-10. doi:10.1016/j.supflu.2015.12.001.

[46] N. Mezzomo, B.R. Mileo, M.T. Friedrich, J. Martínez, S.R.S. Ferreira, Supercritical fluid extraction of peach (Prunus persica) almond oil: process yield and extract composition., Bioresour. Technol. 101 (2010) 5622-32. doi:10.1016/j.biortech.2010.02.020.

[47] G. Liu, X. Xu, Q. Hao, Y. Gao, Supercritical CO2 extraction optimization of pomegranate (Punica granatum L.) seed oil using response surface methodology, LWT - Food Sci. Technol. 42 (2009) 1491-1495. doi:10.1016/j.lwt.2009.04.011.

[48] P. Mitra, H.S. Ramaswamy, K.S. Chang, Pumpkin (Cucurbita maxima) seed oil extraction using supercritical carbon dioxide and physicochemical properties of the oil, J. Food Eng. 95 (2009) 208-213. doi:10.1016/j.jfoodeng.2009.04.033.

[49] L.S. Kassama, J. Shi, G.S. Mittal, Optimization of supercritical fluid extraction of lycopene from tomato skin with central composite rotatable design model, Sep. Purif. Technol. 60 (2008) 278-284. doi:10.1016/j.seppur.2007.09.005.

[50] İ.S. Şanal, E. Bayraktar, Ü. Mehmetoğlu, a. Çalımlı, Determination of optimum conditions for $\mathrm{SC}-(\mathrm{CO} 2+$ ethanol) extraction of $\beta$-carotene from apricot pomace using response surface methodology, J. Supercrit. Fluids. 34 (2005) 331-338. doi:10.1016/j.supflu.2004.08.005.

[51] M. Sun, F. Temelli, Supercritical carbon dioxide extraction of carotenoids from carrot using canola oil as a continuous co-solvent, J. Supercrit. Fluids. 37 (2006) 397-408.

doi:10.1016/j.supflu.2006.01.008. 
[52] S. Bin Lim, S.K. Jung, M.K. Jwa, Extraction of Carotenoids from Citrus unshiu Press Cake by Supercritical Carbon Dioxide, Food Sci. Biotechnol. 12 (2003) 513-520.

[53] A. Ambrogi, D.A. Cardarelli, R. Eggers, Fractional Extraction of Paprika using Supercritical Carbon Dioxide and On-line Determination of Carotenoids, J. Food Chem. Toxicol. ' (2002) 3236-3241.

[54] X. Shi, H. Wu, J. Shi, S.J. Xue, D. Wang, W. Wang, A. Cheng, Z. Gong, X. Chen, C. Wang, Effect of modifier on the composition and antioxidant activity of carotenoid extracts from pumpkin (Cucurbita maxima) by supercritical CO2, LWT - Food Sci. Technol. 51 (2013) 433440. doi:10.1016/j.lwt.2012.11.003.

[55] a. Romo-Hualde, a. I. Yetano-Cunchillos, C. González-Ferrero, M.J. Sáiz-Abajo, C.J. González-Navarro, Supercritical fluid extraction and microencapsulation of bioactive compounds from red pepper (Capsicum annum L.) by-products, Food Chem. 133 (2012) 1045-1049. doi:10.1016/j.foodchem.2012.01.062.

[56] K.D. Sharma, S. Karki, N.S. Thakur, S. Attri, Chemical composition, functional properties and processing of carrot - a review, J. Food Sci. Technol. 49 (2012) 22-32. doi:10.1007/s13197-011-0310-7.

[57] N.C.M.C.S. Leitão, G.H.C. Prado, P.C. Veggi, M. a. a. Meireles, C.G. Pereira, Anacardium occidentale L. leaves extraction via SFE: Global yields, extraction kinetics, mathematical modeling and economic evaluation, J. Supercrit. Fluids. 78 (2013) 114-123. doi:10.1016/j.supflu.2013.03.024.

[58] H. Sovova, Rate of the vegetable oil extraction with supercritical CO2-I. Modelling of Extraction Curves, Chem. Eng. Sci. 49 (1994) 409-414.

[59] T. Baysal, S. Ersus, D. a J. Starmans, Supercritical CO2 extraction of $\beta$-carotene and lycopene from tomato paste waste, J. Agric. Food Chem. 48 (2000) 5507-5511. doi:10.1021/jf000311t.

[60] R. Davarnejad, K.M. Kassim, a. Zainal, S. a. Sata, Supercritical fluid extraction of $\beta$-carotene from crude palm oil using CO2, J. Food Eng. 89 (2008) 472-478. doi:10.1016/j.jfoodeng.2008.05.032.

[61] M.T.O. Jonker, S.B. Hawthorne, A. a Koelmans, Environ. Sci. Technol. 2005, 39, 7889-7895, Environ. Sci. Technol. 39 (2005) 7889-7895. doi:10.1021/es0505191.

[62] K.-Y. Khaw, M.-O. Parat, P.N. Shaw, J.R. Falconer, Solvent Supercritical Fluid Technologies to Extract Bioactive Compounds from Natural Sources: A Review, Molecules. 22 (2017) 1186. doi:10.3390/molecules22071186.

[63] I. Jaswir, D. Noviendri, R. Fitri Hastrini, F. Octavianti, Carotenoids: Sources, medicinal properties and their application in food and nutraceutical industry, J. Med. Plants Res. 5 (2011) 7119-7131. 
